\title{
COnE).(ÖES
}

CIÊNCIA E TECNOLOGIA

\section{UMA SEQUÊNCIA DIDÁTICA GAMIFICADA APLICADA AO ENSINO DE ÓPTICA GEOMÉTRICA}

\author{
Matheus Melo lima, Felipe Moreira Barboza, Dogival Alencar da Silva, \\ Thiago Amaral Melo Lima \\ Instituto Federal de Educação, Ciência e Tecnologia - IFCE \\ <matheusfisicaifce@gmail.com>.<felipebarboza@ifce.edu.br>,<dogivalalencar@bol.com.br> \\ $<$ thiagoamaral.mat@gmail.com> \\ $10.21439 /$ conexoes.v15i0.2088
}

\begin{abstract}
Resumo. No atual cenário educacional é imprescindível o planejamento das atividades didáticas que norteiam o caminho para uma educação de qualidade, auxiliando no ensino-aprendizagem de maneira significativa. No entanto, no ensino das ciências naturais, especificamente no ensino de física, é verificado uma dependência excessiva do livro didático e de aulas expositivas. Assim, foi proposto uma sequência didática a fim de potencializar o ensino de óptica geométrica em uma turma de graduação, utilizando técnicas de gamificação para auxiliar na formação de um aluno mais crítico e reflexivo. Para realizar essa pesquisa de caso, utilizamos: roteiro didático para simulação virtual, palavras cruzadas, Quiz conceitual e listas de exercícios. Ao final, foi aplicado um questionário tendo como objetivo mapear o impacto da aplicação da sequência didática no ensino de óptica geométrica. Verificou-se que a sequência didática gamificada correspondeu aos resultados esperados, proporcionando uma maior participação e envolvimento entre os alunos. Tendo a motivação, como elemento fundamental para alcançar os objetivos de maneira prazerosa e atrativa. Vale ressaltar, que os instrumentos da sequência obtiveram grande aceitação entre os alunos, apontando as palavras cruzadas como instrumento eficaz na revisão conceitual, os quizzes como prática lúdica e motivadora e a importância da utilização da simulação virtual pela autonomia nas mudanças de configurações do sistema sem oferecer risco a si ou ao equipamento. Por isso, essa pesquisa mostra a necessidade de esforços teóricos/práticos que contribuam para a legitimação e ampliação de estratégias gamificadas no ensino de física.
\end{abstract}

Palavras-chaves: Sequência Didática. Gamificação. Óptica geométrica. Simulação virtual.

\section{A GAMIFIED DIDACTIC SEQUENCE APPLIED TO THE TEACHING OF GEOMETRIC OPTICS}

\begin{abstract}
In the current educational scenario it is essential to plan the didactic activities that guide the way to a quality education, helping in teaching-learning significantly. However, in the teaching of natural sciences, specifically in physics teaching, an excessive dependency of the textbook and expository classes is verified. Thus, a didactic sequence was proposed in order to potentiate geometric optical teaching in a graduate class, using gamification techniques to assist in the formation of a more critical and reflective student. To accomplish this case survey, we use: Didactic script for virtual simulation, crosswords, conceptual quiz and exercise lists. At the end, a questionnaire was applied aimed at mapping the impact of the application of the didactic sequence in the teaching of geometric optics. It was verified that the gamified didactic sequence corresponded to the expected results, providing greater participation and involvement among students. Having motivation, as a key element to achieve objectives in a pleasurable and attractive way. It is noteworthy, that the instruments of the sequence obtained great acceptance among students, pointing to crosswords as an effective instrument in the conceptual revision, the quizzes as a playful and motivating practice and the importance of using the virtual simulation by autonomy in the changes in system configurations offer risk to themselves or equipment. Therefore, this research shows the need for theoretical / practical efforts that contribute to the legitimacy and expansion of gamed strategies in physics teaching. oferecer risco a si ou ao equipamento.
\end{abstract}

Keywords: Following teaching. Gamification. Geometric optics. Virtual simulation.

\section{INTRODUÇÃO}

Os debates sobre ensino e aprendizagem vêm ganhando cada vez mais espaço na sociedade. De fato, muito se discute sobre as deficiências, fragilidades e dificuldades do ensino atual, etiquetando o "ensino tradicional" com o estereótipo de negativista e insuficiente (SILVA; SALES; ALVES, 2018). Essa realidade 
vem perpassando os séculos, de modo a afetar diversas áreas do conhecimento. No ensino de exatas, o currículo preza por uma quantidade excessiva de conteúdo, sendo estes ministrados na maioria das vezes de forma expositiva seguindo um modelo de respostas prontas. Essa realidade também está presente no ensino de física. Diogo e Gobara (2007), evidencia que o ensino das ciências físicas e naturais está fortemente influenciado pela dependência excessiva do livro didático, método expositivo e um currículo desatualizado e descontextualizado.

Nesse contexto, visando contribuir de maneira significativa para a aprendizagem, devemos nos apoiar em metodologias construtivistas, trabalhos como o de Nascimento et al. (2020) utilizam a gamificação, através de um jogo lúdico, como recurso metodológico para facilitar a aprendizagem dos alunos do ensino médio. Sales et al. (2017) apresenta uma metodologia, com foco no aluno como ser ativo, com o uso da gamificação e as Tecnologias de Informação e Comunicação para motivar o ensino de física nas turmas de ensino médio integrado do Instituto Federal do Ceará.

Considerando o pressuposto, se faz importante a utilização das Tecnologias Digitais de Informação e Comunicação (TDIC) em ambientes educacionais, tendo em vista o seu potencial para a melhoria da aprendizagem, e pelo fato de as tecnologias digitais já fazerem parte do cotidiano dos jovens. Studart (2015) defende que o uso das TDIC na educação contribui para tornar o aluno motivado, engajado e colaborativo, por conseguinte, aumenta a efetividade no processo de ensino e aprendizagem. Sales et al. (2017) reforça ser interessante um ambiente em que os alunos utilizem metodologias ativas e tecnologias digitais.

Motivados pelo contexto discutido acima, esse artigo tem como objetivo geral mapear o impacto da aplicação de uma sequência didática gamificada no ensino de óptica geométrica, durante 2 meses em uma turma do $6^{\circ}$ semestre do curso de Licenciatura em Física do Instituto Federal de Educação, Ciência e Tecnologia do Ceará (IFCE), Campus-Tianguá. Buscamos também elencar as possibilidades da gamificação para o processo de ensino-aprendizagem aplicada a óptica geométrica e fomentar uma reflexão sobre o ensino de física utilizando instrumentos de gamificação. Nessa visão, foram desenvolvidas atividades divididas em etapas, por meio de uma sequência didática, que utilizam um roteiro didático para simulação virtual, palavras cruzadas, Quiz conceitual e listas de exercícios. Essas ferramentas visam melhorar a realidade do ensino e proporcionar um ambiente interativo de aprendizagem significativa, possibilitando que o aluno mantenha o conhecimento por um período maior, dando sentido ao que é aprendido.

\section{FUNDAMENTAÇÃO TEÓRICA}

A Sequência Didática surgiu na França no início dos anos 80 com o objetivo de melhorar o processo de ensino da língua materna, de modo que alterasse o seu modo fragmentado de abordagens dos conteúdos dentro da sala de aula (DOLZ; NOVERRAZ; SCHNEUWLY, 2004). Essa proposta inovadora teve muita resistência no início, devido ao forte tradicionalismo ainda presente na educação, porém aos poucos, ela foi quebrando as barreiras e sua aceitação entre os estudiosos da didática e pedagogia foi aumentando. Contudo, somente a partir da década de 90, mais precisamente com a publicação dos Parâmetros Curriculares Nacionais (PCNs) em 1992, a sequência didática começa a ser trabalhada no Brasil (OLIVEIRA, 2013).

A Sequência Didática consiste do planejamento de etapas que irão compor um conjunto de atividades conectadas entre si que podem ser organizadas de acordo com os objetivos que o professor busque alcançar, e assim, possibilitará diversas formas de intervenção em sala de aula. Essa proposta teórico metodológica auxilia na investigação do trabalho docente, proporcionando uma conscientização na maneira de pensar o ensino da física e aproximando a teoria da prática, visando superar à abordagem ultrapassada cujo foco é a memorização e decodificação de fórmulas.

Dessa maneira, foi desenvolvida uma Sequência Didática através de uma perspectiva processual e significativa, Ausubel, Novak e Hanesian (1980) aborda a necessidade de a aprendizagem ocorrer com significados, tendo uma interação cognitiva entre o novo conhecimento e algum conhecimento prévio especificamente relevante para a estrutura cognitiva do aluno. Por esta razão, buscamos através dos instrumentos dessa sequência didática despertar a predisposição em aprender tópicos da óptica geométrica.

\subsection{Gamificação}

Os jogos em geral são uma maneira muito popular de entretenimento e atrai públicos de diversas idades, devido ao seu caráter lúdico e desafiador. Com isso, a aplicação de jogos envolvendo a física proporciona uma sensação de mudança quanto à situação formal de ensino na sala de aula, auxiliando na transformação da diversão em aprendizagem.

O jogo pode ser considerado um auxiliar educativo e uma forma de motivar os alunos para a aprendizagem. Nesse prisma, não se deve considerar apenas como um divertimento ou um prazer. Deverá ser associado a uma ativi- 
dade com determinados objetivos a atingir e um meio de aprendizagem. (PEREIRA 2013 p. 21).

O jogo quando aplicado na sala de aula, motiva os alunos gerando um maior interesse pela física, aumentando as chances da aprendizagem de novos conceitos, conteúdos e habilidades. Isso acontece porque o jogo possui aspectos do cotidiano e esse envolvimento desenvolve o interesse dos alunos. Dividir os estudantes em grupos surge como uma possibilidade para que o professor possa facilitar o processo de mediação do processo de gamificação, observando e avaliando tanto a atividade, bem como diagnosticando as possíveis dificuldades. Para Schaeffer (2006) os alunos podem ser organizados em grupos, de forma a trabalharem com o respeito e cooperação, aprendendo a viver e crescer conjuntamente nas relações educacionais e socias, proporcionando o desenvolvimento de importantes aspectos para uma vida em sociedade. De acordo com Brenelli, os alunos encontram a oportunidade de se desenvolver, pois:

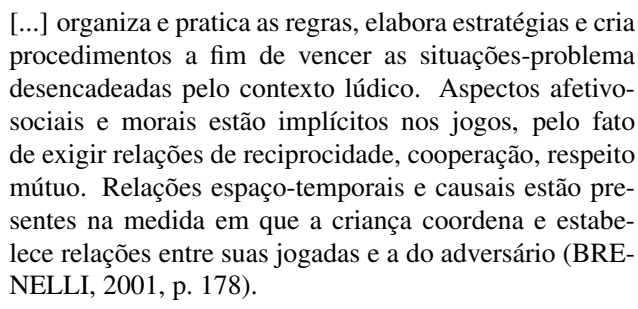

Contudo, a aplicação dos jogos educativos sem uma base metodológica nem irá motivar os alunos nem irá complementar os conhecimentos vistos em sala de aula. Para isso é preciso que o professor ao utilizar os jogos, planeje sua aplicação envolvendo desafios que motivem e estimulem o aprendizado (GARCIA, 2015). Pensando em uma sequência didática que contemple esse aspecto lúdico e principalmente para que ela não se torne um mero jogo. Faz-se necessário adotar a gamificação visando uma adequação das estratégias didáticas.

Quando a gamificação é adotada, há a necessidade de adequação das estratégias didáticas aos diversos contextos das propostas pedagógicas. O professor, em consonância com os conteúdos digitais e com as inovações emergentes, conseguirá promover e incrementar o entusiasmo e o interesse dos alunos (GARCIA, 2015, p. 37).

Nesse sentido, a gamificação associa os conceitos e habilidades dos games ao ensino. Ou seja, ela aplica noções dos games em situações diversas. O professor ao planejar uma aula gamificada, não precisa ser um designer, mas, ter uma presença questionadora para que ao aplica-la na sala de aula, consiga tornar os alunos motivados a promover o conhecimento. Durante a aplicação dos instrumentos desta sequência didática, vários aspectos da gamificação, como a competição construtiva, fator motivacional, aspecto lúdico e feedback são facilmente identificados, proporcionando que os alunos do século XXI sintam-se motivados e interessados ao realizar as atividades propostas.

\subsection{Simulação virtual}

O uso da tecnologia na educação é uma ferramenta pedagógica que aperfeiçoa o ensino-aprendizagem. Sua utilização pode ser feita em diversos momentos já que pode ser utilizada em vários lugares, podendo o aluno observar fenômenos que não seriam possíveis sem laboratórios bem estruturados ou com grandes aparatos experimentais. Umas das características que torna a física de difícil entendimento, é a de lidar com conceitos abstratos, algumas vezes contra intuitivos, os quais exigem uma grande capacidade de interpretação. Essa dificuldade também é notada com os alunos ingressantes na graduação (MIRANDA; VANIN; BECHARA, 2004).

Assim, o acesso a boas simulações contribui para solucionar diversas questões no ensino das ciências. Quando o aluno passa a utilizar essa tecnologia, ele melhora o seu entendimento sobre os diferentes aspectos do sistema, pois ao mudar as condições da simulação, ele vai não só responder as questões impostas no roteiro, mas vai pesquisando, testando e criando outras situações problemas, de modo a aprimorar seu conhecimento. Alguns pesquisadores chegam a sugerir que alguns experimentos de bancada sejam substituídos por seus equivalentes virtuais (YAMAMOTO; BARBETA. 2001).

As simulações podem contribuir no desenvolvimento dessa capacidade de chegar a conceitos abstratos mais gerais da Física, ao permitir que o estudante investigue a realidade do sistema observando-o diretamente, promovendo mudanças nas suas condições específicas, e observando suas consequiências. (MIRANDA; VANIN; BECHARA, 2004, p. 2).

Além da possibilidade vista acima, o professor também pode fornecer um feedback para aperfeiçoar a compreensão dos conceitos visto durante a simulação.

\subsection{Quiz conceitual}

Partindo da facilidade dos alunos de interagir com os dispositivos móveis (celular, tablet, iPhone, note- 
book). Um instrumento de suma importância no ensinoaprendizagem é o Quiz, que pode ser entendido como:

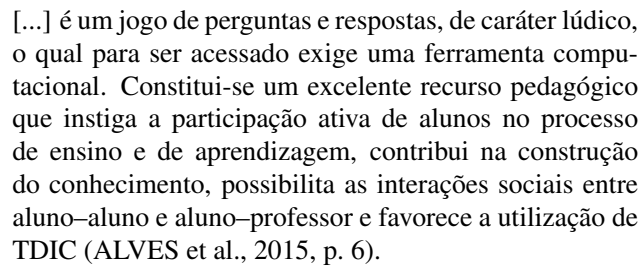

O Quiz pode ser aplicado para fazer uma avaliação do conhecimento do aluno sobre determinado tópico. Ele é um jogo de perguntas, uma espécie de questionário. Os alunos podem participar individualmente ou mesmo em grupos. Além disso, o professor pode adequar o tempo de resposta aos questionamentos. Esse tipo de jogo (Quiz), possibilita uma experiência divertida e atraente por meio da competição. Estima a construção de conhecimento colaborativo, de forma que é possível avaliar a aprendizagem do conteúdo abordado de maneira lúdica (OLIVEIRA; JUNIOR; SCHIMIGUEL, 2012). É válido destacar também que essa ferramenta gera estatísticas imediatas que permitem o professor acompanhar/avaliar os erros e acertos, podendo verificar a questão que obteve mais erros e as que obtiveram mais acertos, verificando se os conteúdos conceituais estão sendo compreendido pelos alunos.

\subsection{Palavras cruzadas}

As palavras cruzadas ou cruzadinhas, é um jogo de adivinhar e cruzar palavras em linhas horizontal e vertical, podendo ou não conter espaços entre as construções. Ao ler as dicas, o jogador vai complementando as lacunas para preencher todas as palavras. A utilização das palavras cruzadas tem por objetivo desenvolver diversas habilidades do usuário, como por exemplo a memória e o raciocínio. Além de propiciar a interação entre os alunos.

[...] a aplicação das palavras cruzadas como mecanismo de transposição didática no ensino de física, pois os estudantes participaram efetivamente das aulas, nas discussões propostas em sala e ainda nas leituras textuais, deixando evidencias que as atividades lúdicas com interações tecnológicas facilitam o processo de ensino aprendizagem (CORREIA 2016 p. 36).

Quando esse suporte metodológico é utilizado de forma lúdica, ele colabora significativamente para a compreensão dos conceitos. Na educação, as palavras cruzadas funcionam como um apoio didático, pois provoca o estímulo cognitivo, auxiliando na compreensão e coordenação dos conceitos estudado, sendo uma forma divertida de aprender que pode ser utilizada dentro e fora da sala de aula. Os alunos conseguem reconhecer seus erros, visto que quando sobra alguma lacuna (espaço vazio) no exercício ela sabe que falta alguma coisa na escrita correta.

\section{METODOLOGIA}

Com o intuito de atingir os objetivos propostos optou-se, quanto à abrangência da pesquisa, em ser realizado um estudo do caso, de natureza qualitativo e quantitativo a partir da aplicação de uma sequência didática gamificada, considerando os dados qualitativos gerados pelas colocações dos alunos e quantitativos a partir da análise dos questionários. Esse estudo foi realizado com 17 licenciando de uma turma de física do $6^{\circ}$ semestre do curso de Licenciatura em Física do Instituto Federal de Educação, Ciência e Tecnologia do Ceará (IFCE). As atividades da sequência didática foram desenvolvidas durante dois meses do semestre letivo na disciplina de Ondas e Óptica, tendo uma carga horária semanal de 4 horas. O conteúdo abordado versou sobre a área da física denominada de Óptica Geométrica, mais especificamente sobre os assuntos: Propagação Retilínea da Luz; Reflexão, Refração; Espelhos Planos e Esféricos; Lentes Delgadas.

A sequência didática foi dividida em etapas, afim de obter um melhor controle e possibilitar um feedback ao final de cada etapa. A primeira refere-se ao diagnóstico dos sujeitos da pesquisa. A segunda trata da aplicação da metodologia destacando a revisão dos conteúdos e conceitos. A terceira diz respeito a avaliação e a quarta descreve sobre o questionário aplicado aos discentes.

\subsection{Primeira etapa}

No primeiro momento da aplicação dessa sequência didática, apresentou-se aos alunos o plano de ensino da disciplina. Em seguida, foi feita uma explanação sobre as atividades propostas (missões) que eles teriam que realizar. Para isso, os estudantes foram divididos em grupos de no máximo 4 pessoas com o objetivo de que todos os componentes do grupo colaborassem para uma aprendizagem mais satisfatória.

Adiante, foi disponibilizado aos grupos um roteiro (Figura 1, tomando-se como base duas simulações virtuais, sobre os assuntos: refração da luz e lentes delgadas. A escolha desses temas se deu pelos questionamentos dos alunos e porque o professor entende que esses assuntos são facilmente relacionados com os temas abordados nos outros instrumentos. O roteiro, além do passo a passo para realizar a atividade, sugeria perguntas através de situações sobre os fenômenos observados que buscam instigar os alunos a manifestar seus co- 
nhecimentos prévios, para que estes sejam usados como ponto de partida pelo professor. Ao manusear o roteiro os alunos podiam alterar as características do sistema, de forma a testar várias possibilidades no ambiente virtual. Foi utilizado a simulação interativa do projeto Physics Educacional Technology (PhET) da Universidade do Colorado.

\subsection{Segunda etapa}

Após a conclusão da primeira etapa, o professor abordou o conteúdo dando ênfase aos princípios e formulações matemáticas da Óptica Geométrica, bem como as aplicações no dia a dia, procurando sempre ministrar as aulas de maneira dialogada, ou seja, visando sanar as possíveis dúvidas através das discussões durante a aula. Depois, foi proposto a realização de listas de exercícios sobre os princípios da óptica geométrica, reflexão e refração da luz. Sendo estas previamente selecionados a partir de diferentes níveis de dificuldade. No segundo momento, foi aplicado as palavras cruzadas (Figura 2), envolvendo assuntos como espelhos planos, esféricos e lentes delgadas, utilizamos o suporte do Hot Potatoes, um software educacional canadense utilizado para criar exercícios sob a forma de objetos digitais.

Os alunos preencheram a cruzadinha, partindo das dicas expostas e do conteúdo exposto pelo professor durante as aulas. A intenção dessa etapa, foi aprofundar o conhecimento sobre a Óptica Geométrica, através das discussões propostas pelo professor e utilizar o recurso das palavras cruzadas como um mecanismo auxiliar na revisão dos conteúdos conceituas que foram abordados durante a disciplina. Outro ponto a destacar é que sua realização pode ser em qualquer ambiente, não necessariamente na sala de aula, podendo também consultar as mais diversas fontes de informações, de modo a atingir o objetivo proposto pelo instrumento.

\subsection{Terceira etapa}

Uma das avaliações adotadas foi a aplicação de um quiz que tinham como foco avaliar a aprendizagem de definições e conceitos utilizando o Quizziz. Trata-se de uma ferramenta digital online gratuita que possibilita a criação de questionários dinâmicos com a proposta de ensino gamificado. Esse instrumento foi utilizado como forma de avaliação, destacando as potencialidades e fragilidades dos alunos, no que se refere aos conceitos da Óptica Geométrica. O Quizziz funciona em todos os dispositivos com um navegador, incluindo computadores, tablets e smartphones e adota um formato que condiz com as demandas educacionais atuais, que dialoga com anseios dos estudantes nativos digitais. Este recurso pode ser útil em diversas metodologias de ensino.

O Quizziz mostra as perguntas na tela de cada aluno (Figura 3), para que os alunos possam responder às perguntas em seu próprio ritmo e analisar suas respostas no final. Ainda disponibiliza imagens que realizam o feedback após a escolha do jogador, além da Avatar para cada personagem, tornando o jogo mais lúdico e atrativo. O professor pode utilizar uma quantidade ilimitada de palavras, imagens e gif na elaboração dos questionamentos. Além disso, é possível acessar os relatórios que fornecem informações detalhadas sobre o nível (aprendizagem) do grupo/aluno. Os downloads dos relatórios podem ser realizados em formato de uma planilha do Excel. O propósito de utilizar os assuntos: refração da Luz e espelhos esféricos no quiz é validar os conhecimentos adquiridos através do roteiro virtual e das palavras cruzadas.

\subsection{Quarta etapa}

A última etapa se refere a uma avaliação a partir do olhar do aluno sobre a sequência didática gamificada partindo da aplicação de um questionário. A abordagem utilizada foi de caráter quantitativo. O questionário foi composto por 7 questões, sendo esse fechado e semiestruturado utilizando a escala Likert. Os níveis de concordância foram dispostos em três: 'Concordo', 'Concordo parcialmente' e 'Discordo'. A escala Likert é um recurso que nos permite medir as atitudes, interesses e conhecer o grau de conformidade do entrevistado com as afirmações propostas.

O Questionário foi criado na perspectiva de avaliar a opinião dos alunos a respeito dos instrumentos que formaram a sequência didática, assim como a sequência didática gamificada em si e sobre o trabalho em grupo. O intuito geral foi o de fazer implicações sobre as contribuições acerca da utilização da sequência para o ensino-aprendizagem.

\section{RESULTADOS E DISCUSSÃO}

Nesta seção apresentaremos os dados oriundos da aplicação do questionário na amostra de alunos, discutiremos e interpretaremos esses dados à luz das contribuições teóricas que nortearam a fundamentação teórica deste artigo.

A primeira afirmativa foi: "A formação de grupos durante as aulas ajudou no aprendizado dos conteúdos." A maioria dos discentes elucidaram que a formação de grupos facilitou a aprendizagem (objetivo da intervenção), pois $75 \%$ explicitaram 'Concordo', 19\% 'Concordo parcialmente' e apenas 6\% 'Discordo'. 

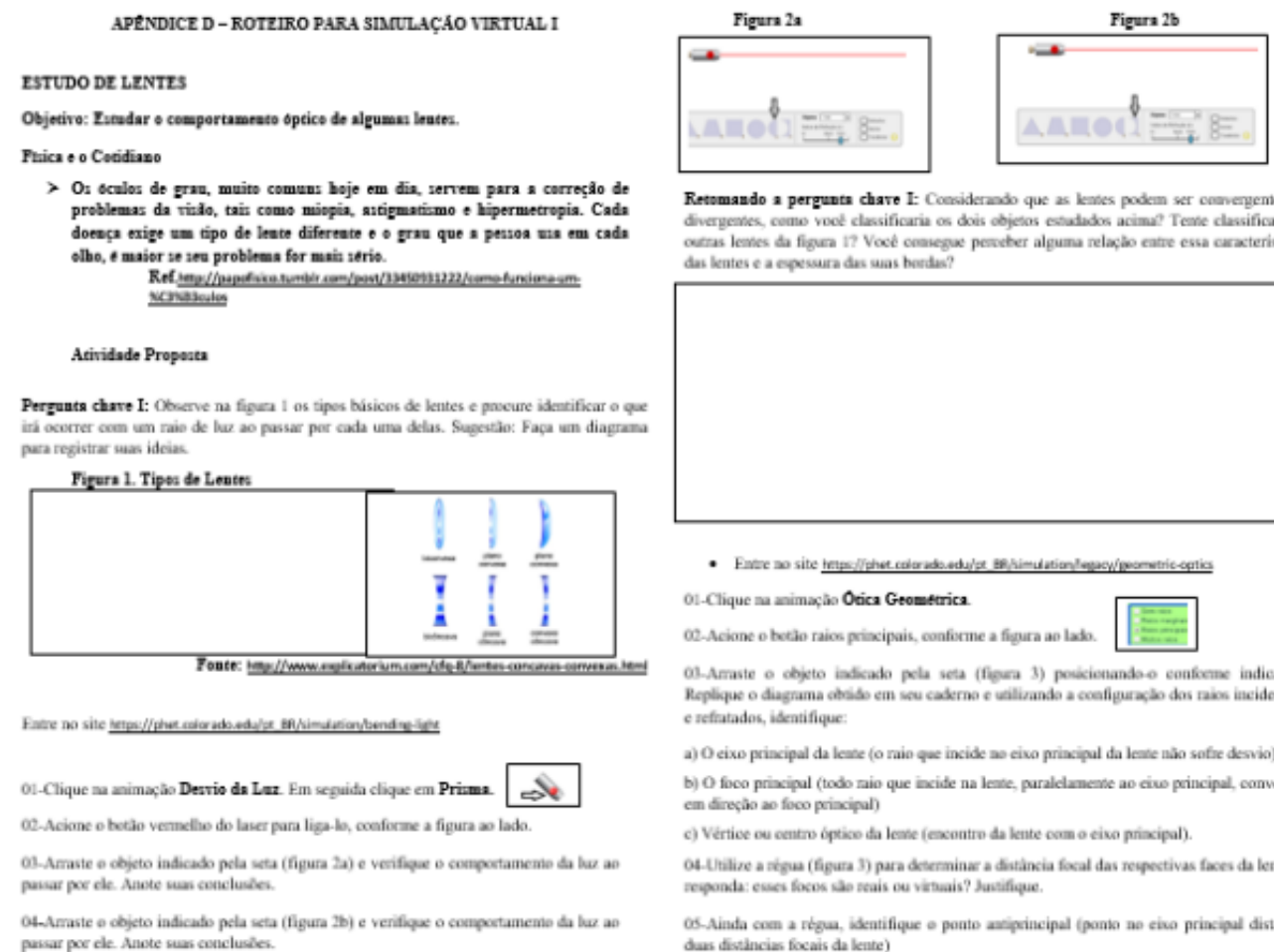

Retomando a perguta chave IE Coessiderando que as kentes podem ser cenvengemes diveryentes, come vook classificaria os dois objesos estudubs acime? Tene classificar a das ientes e a eperuira das was herdes?

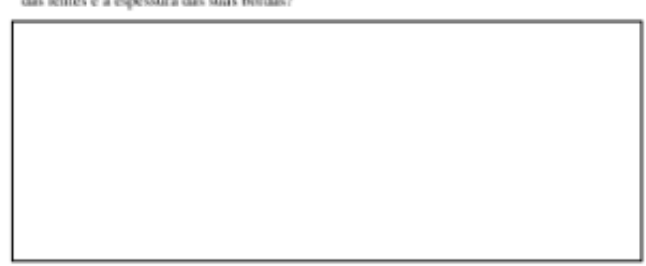

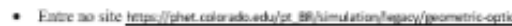

01-Clique ma mimaç h̀s Otica Geometrica

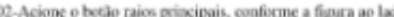

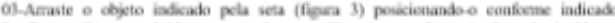

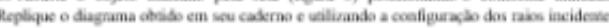
e aefatados, ideatifique

a) Oeixo principal da leste (o raie que incide as eivo prixipul da lente nầo sofbe deswio). b) $O$ foco prixipal (todo aio que ixcide na lente, paraldanenese ae ciw perincipal, converge en direçầ as foco prixipal)

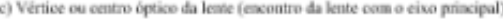

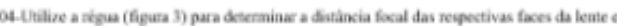

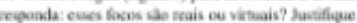

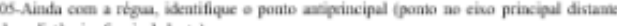
dus divinocis foceais de kente)

Figura 2: Palavras cruzadas.

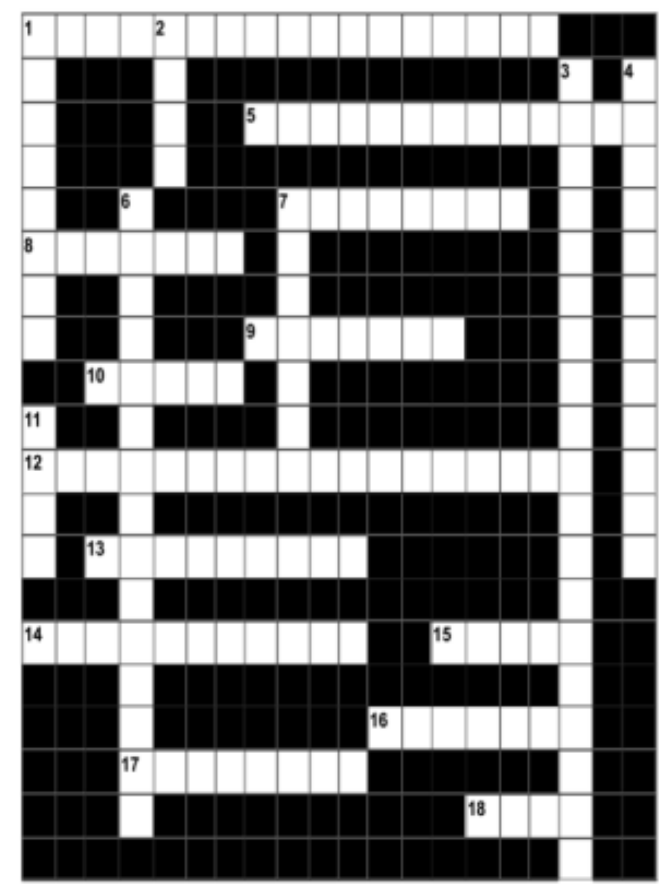

Across:

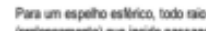

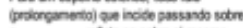
A.

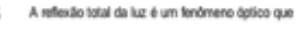

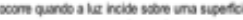
come Hesta. et convietarerto

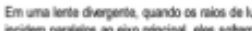

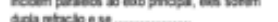

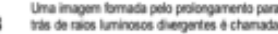

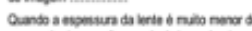

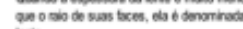

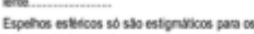

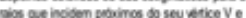

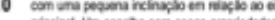

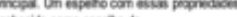

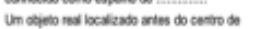

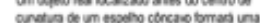
ungm

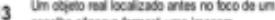

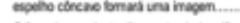

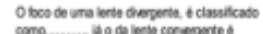

(4)

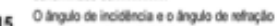

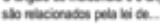

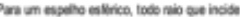

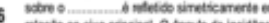

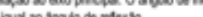

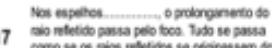

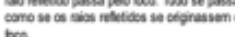

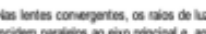

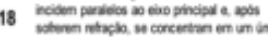
portio mite portio io

Down:

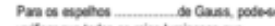

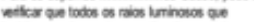

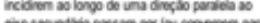

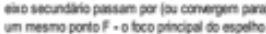

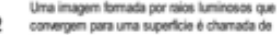
inapen -

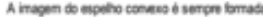

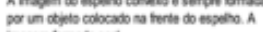
inspon brata sear

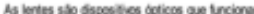

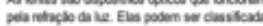

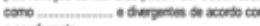

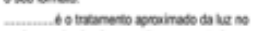

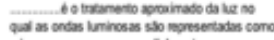

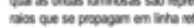

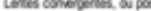

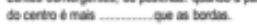

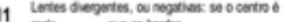



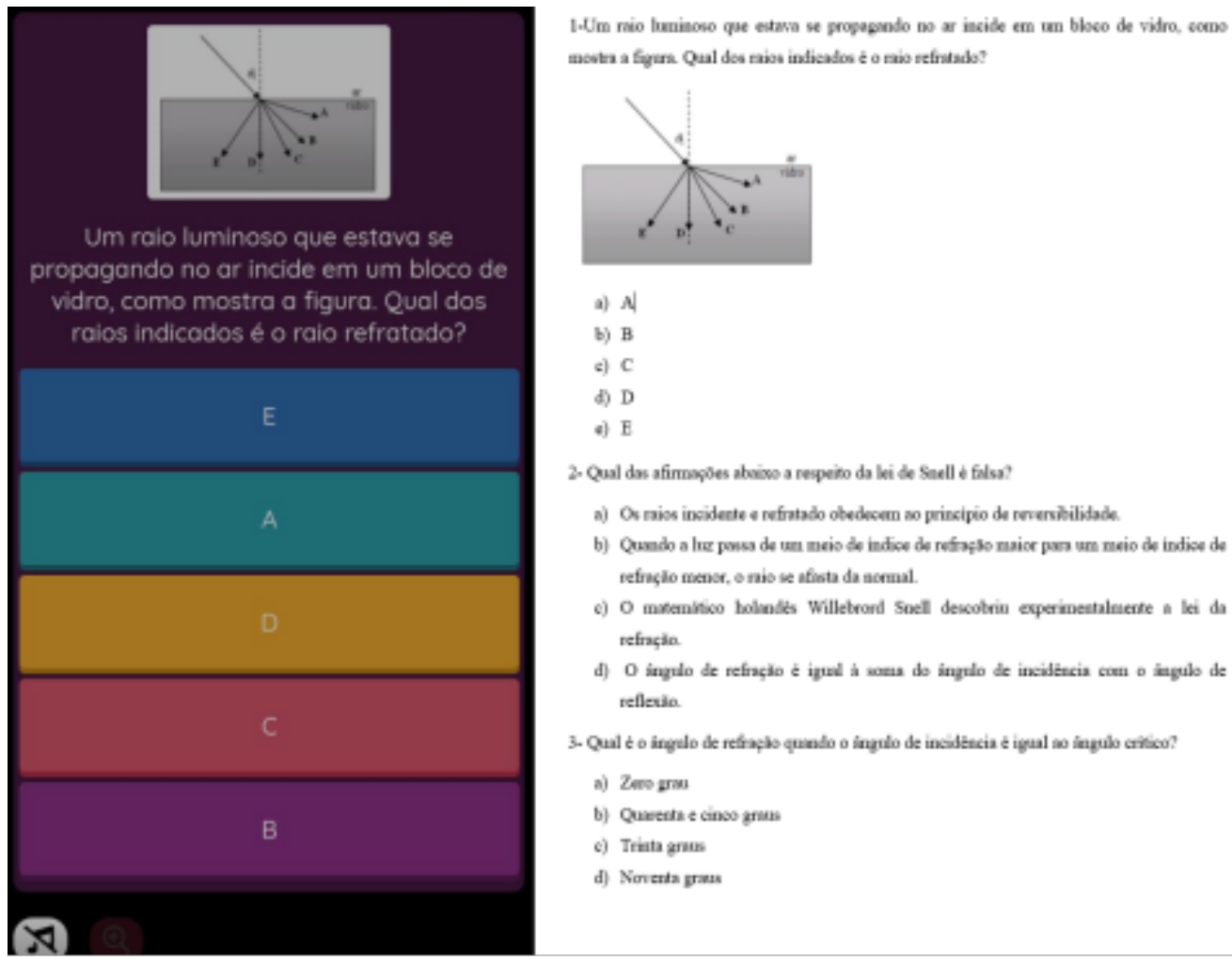

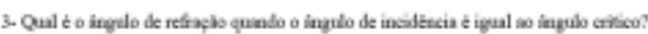

a) Zes gras

b) Quecth e cinoo gram

c) Triata grass

d) Nenerta prase

Figura 4: Relativo à formação de grupos para melhoria da aprendizagem.

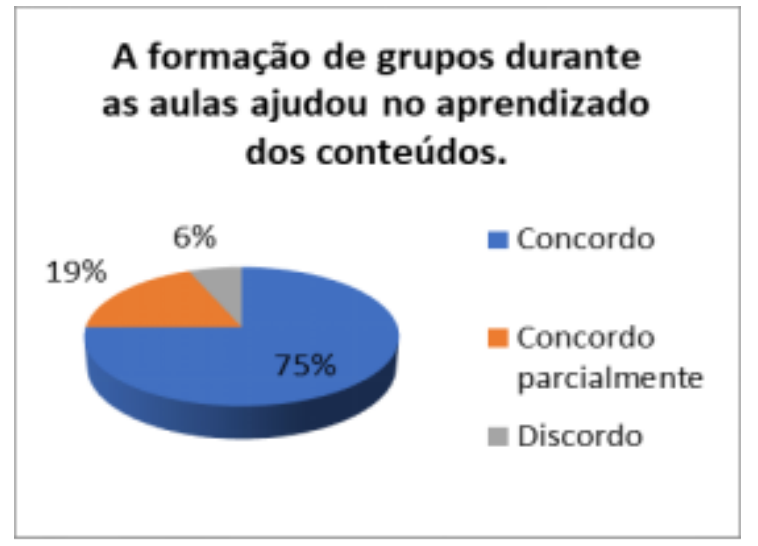

Esses dados mostraram que o processo de ensinoaprendizagem se tornou mais atrativo e dinâmico segundo (OLIVEIRA, 2013), visto que a formação de grupos é uma maneira de construir o conhecimento de forma coletiva, estimulando a competição construtiva e o respeito à opinião dos colegas. Motivando-os dessa forma, a questionarem, responderem questionamentos caracterizando uma dinâmica atípica em muitas situa- ções didáticas tradicionais. Vale destacar que os $6 \%$ dos alunos que não concordaram que a formação de grupos facilitou a construção da aprendizagem, afirmaram que preferem estudar individualmente, por conta da dificuldade em se relacionar com os outros, relatando a falta de empatia entre eles pela divergência das opiniões e personalidades. Ressaltamos ainda que, a maioria se manifestou de forma positiva a utilização das atividades em grupo.

As próximas três afirmativas buscam analisar os instrumentos que compõem a sequência didática gamificada.

Iniciamos com a afirmativa: A simulação virtual melhorou sua concepção sobre a Óptica Geométrica. Os dados mostraram que 94\% indicaram 'Concordo' e 6\% 'Concordo parcialmente'. Nesse contexto, os dados apontam que a simulação virtual é uma importante ferramenta para o ensino de física. Através dela é possível uma abordagem mais clara dos fenômenos, podendo também contornar algumas dificuldades que o experimento concreto oferece. Outra grande vantagem alegada pelos alunos é a possibilidade de alterar as variáveis do sistema de forma rápida e prática, para assim observar as mudanças no comportamento do fenômeno. Assim como destacaram Miranda, Vanin e Be- 
Figura 5: Referente à simulação virtual.

\section{A simulação virtual melhorou sua concepção sobre a Óptica Geométrica.}

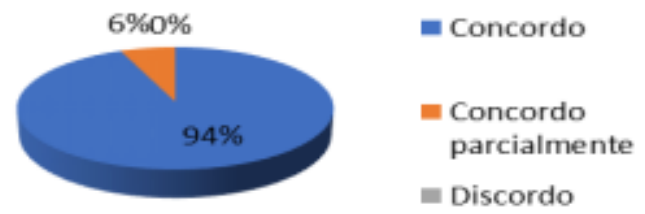

chara (2004).

Os alunos ainda relataram que tem mais liberdade durante a manipulação do sistema, já que a simulação não oferece risco de danificar o equipamento. A terceira afirmativa do questionário foi: As palavras cruzadas contribuíram para a revisão dos conceitos e definições relacionados ao tema proposto nas aulas. O gráfico 3 mostra que 100\% responderam 'Concordo'.

Figura 6: Referente às palavras cruzadas.

\section{As palavras cruzadas contribuíram para a revisão dos conceitos relacionados ao tema proposto nas aulas.}

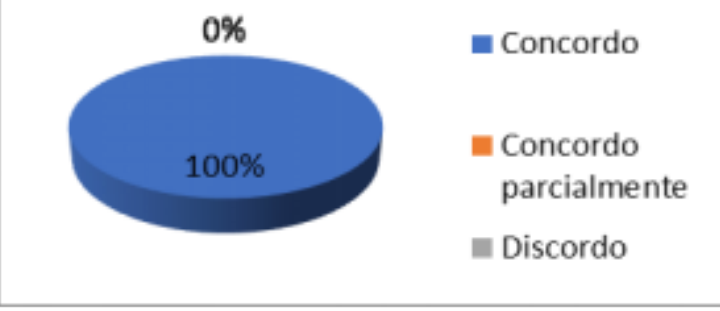

Os dados acima evidenciam a importância dos jogos na educação. Pois segundo Correia (2016) as atividades lúdicas com interações tecnológicas facilitam o processo de ensino e aprendizagem. As palavras cruzadas contêm características da gamificação, tornando-se assim lúdica e atraente. Ela permite que o aluno revise os conceitos e definições vistos em sala de aula a qualquer hora e em qualquer ambiente.

Dando prosseguimento a análise dos dados obtidos, consideremos a quarta afirmativa: A aplicação do Quiz como avaliação contribuiu para sua aprendizagem. Os resultados adquiridos mostraram que $88 \%$ responderam
'Concordo', 6\% 'Concordo parcialmente' e 6\% 'Discordo'.

Figura 7: Relativo à aplicação do Quiz conceitual como forma de avaliação.

\section{A aplicação do Quiz como avaliação contribuiu para sua aprendizagem.}

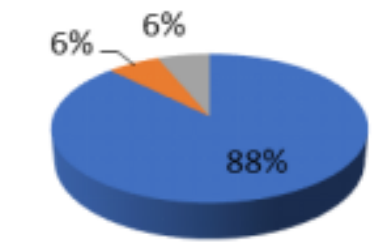

\section{- Concordo \\ - Concordo parcialmente \\ Discordo}

A grande maioria mostra-se interessado ao usarem o Quiz como um mecanismo de avaliação, destacando pontos como a praticidade, rapidez na apresentação dos resultados e possibilidade de contextualização das questões com figuras, textos e outros. Petri et al. (2016), traz que o uso do quiz é uma atividade benéfica, eficaz e motivadora, possibilitando a participação ativa e um maior envolvimento dos alunos durante a avaliação. $\mathrm{O}$ uso de material desse caráter torna-se bastante importante na construção do conhecimento e deve ser usado como uma estratégia utilizada por professores (NASCIMENTO et al. 2020).

As próximas três sentenças abordaram a respeito da sequência didática, não de forma fragmentada, mas como um todo. Assim, a quinta afirmativa foi: A utilização da Sequência didática gamificada mostrou-se uma importante ferramenta para o ensinoaprendizagem. As respostas mostraram que $81 \%$ responderam 'Concordo' e 19\% 'Concordo parcialmente'.

Os resultados comprovam que a sequência didática gamificada foi bem aceita entre os alunos, evidenciando a importância de metodologias dinâmicas, ativas, reflexivas e lúdicas no ensino da física. Oliveira (2013) defende ainda que através da sequência pode-se utilizar diversas formas de intervenção para as atividades, podendo destacar a professor-aluno, para que os conhecimentos e habilidades propostas possam ser trabalhados de forma significativa. A sexta afirmativa foi: $\mathrm{O}$ recurso do feedback durante toda a sequência didática, ajudou a sanar as dúvidas sobre o assunto abordado. Os resultados mostraram que $87 \%$ responderam 'Concordo' e $13 \%$ 'Concordo parcialmente'.

Com a implementação do feedback durante toda a sequência didática os erros que os alunos cometeram 
Figura 8: Referente a importância da sequência didática para $\mathrm{o}$ ensino-aprendizagem.

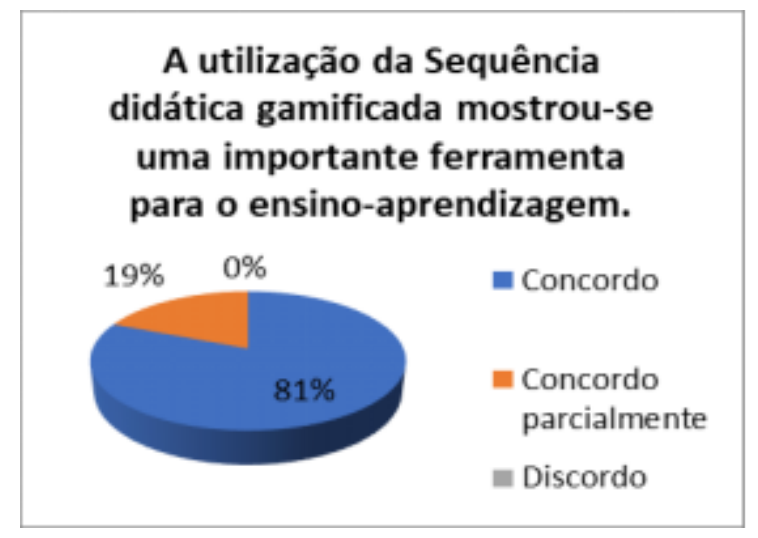

Figura 9: Referente ao feedback durante a sequência.

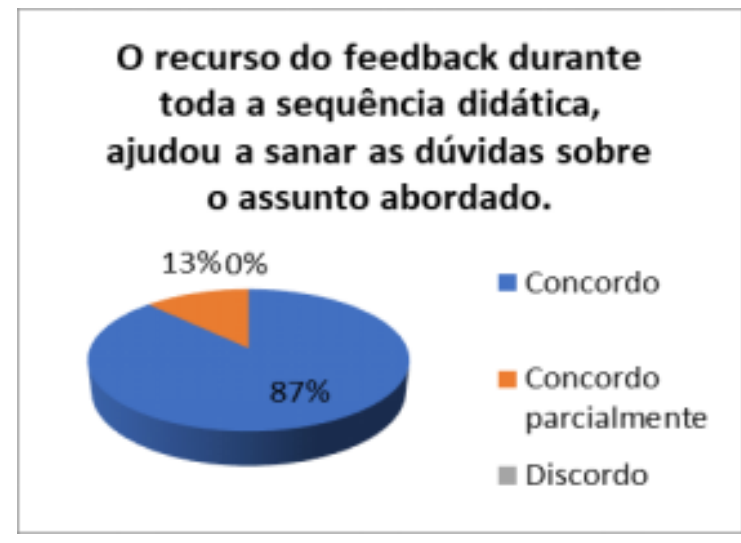

durante alguma etapa ou exercício, não foram descartados e sim aproveitados para discutir o assunto, visando debater os pontos que não ficaram claros e destacando os comportamentos positivos, gerando assim uma conscientização no que tange o ensino-aprendizagem. $\mathrm{O}$ feedback também foi aplicado pelos próprios alunos durante a atividade, contribuindo para uma maior cooperação no trabalho em grupo.

Para finalizarmos nossa discussão, consideremos a sétima afirmativa: A ordem estabelecida na Sequência Didática contribuiu efetivamente para a aprendizagem. O gráfico mostra que $94 \%$ dos entrevistados indicaram 'Concordo', 6\% ‘Concordo parcialmente'.

Os resultados foram de acordo com a ótima aceitação dos alunos durante toda a metodologia proposta. Para Oliveira (2013) é necessário um planejamento para cada etapa ou atividade que será desenvolvida na sequência didática. E pelos resultados, constatamos que a ordem estabelecida foi capaz de respeitar a relação entre os conhecimentos prévios dos participantes e os no-
Figura 10: Referente à ordem da Sequência didática.

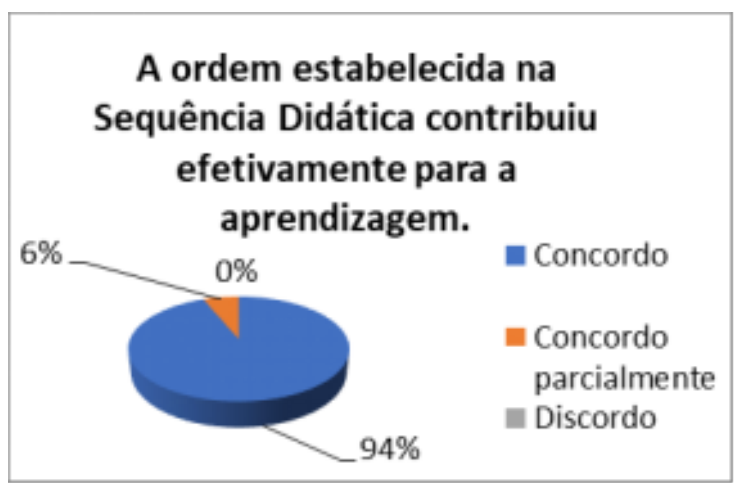

vos conteúdos e habilidades que foram desenvolvidos.

\section{CONSIDERAÇÕES FINAIS}

As categorias abordadas na pesquisa evidenciaram que a gamificação é um fator positivo para a construção da aprendizagem na física, especificamente no ensino de óptica geométrica. Isso é atribuído as vantagens do uso da gamificação, como a capacidade de atrair o público de diversas idades, motivando-os pelos assuntos da física. Com isso, ele desenvolve algo fundamental na relação professor-aluno que é a motivação, proporcionando que os discentes atinjam seus objetivos de forma prazerosa e atrativa.

Com isso, a pesquisa atingiu seu objetivo geral, conseguindo mapear o impacto da sequência didática, através de uma análise qualitativa e quantitativa e atendeu aos objetivos específicos, que foram evidenciados durante a análise do questionário e serão comentadas nos parágrafos abaixo. A pesquisa mostrou que os sujeitos de pesquisa se manifestaram de maneira muito positiva quanto à aplicação de uma sequência didática utilizando a gamificação, evidenciando que os métodos ativos facilitam a aprendizagem, pois são reflexivos, lúdicos e dinâmicos.

Constatamos durante a aplicação e posteriormente na análise do questionário que o roteiro para a simulação virtual é um método ativo muito significativo para a aprendizagem, pois, proporciona liberdade para modificar as variáveis do sistema de forma simples, rápida e sem oferecer risco a si ou ao equipamento. Podendo o aluno extrair o máximo dos experimentos. As palavras cruzadas foi o elemento que obteve resultado unanime, $100 \%$ dos alunos concordaram totalmente com sua utilização para a revisão dos conceitos, comprovando seu valor para a compreensão e coordenação dos conceitos estudados nas aulas. Isso se deve, em grande parte, graças à intervenção que acontece imediatamente após o 
preenchimento das lacunas, quando os espaços não se encaixam com a palavra utilizada, o aluno percebe seu erro e procura corrigir.

O quiz conceitual como avaliação oferece vários benefícios aos alunos, como a praticidade, o caráter lúdico, dinâmico e desafiador, proporcionando uma participação ativa e um maior envolvimento dos alunos, além de desenvolver a contextualização através de imagens, gifs e avatares para o caso do aluno que não queira se identificar. De forma adicional, o professor pode acompanhar (em tempo real) as questões que tiveram mais erro e mais acertos, auxiliando no feedback e na identificação das fragilidades e potencialidades da metodologia.

Entretanto, é válido ressaltar que todos os instrumentos obtiveram resultados positivos, concentrado a maioria das opiniões em concordo. Vale destacar ainda que as palavras cruzadas foram utilizadas numa perspectiva de revisão, já o quiz conceitual em uma concepção de avaliação somativa. Isso influencia na aceitação dos discentes, já que infelizmente está na cultura do aluno esse receio por avaliações. Conclui-se que a sequência didática gamificada como metodologia ativa, correspondeu aos resultados esperados, tendo um impacto significativo no ensino-aprendizagem auxiliando na formação de um aluno ativo e crítico.

\section{REFERÊNCIAS}

ALVES, R. M. M.; GEGLIO, P. C.; MOITA, F.; SOUZA, C.; ARAÚJO, M. O quiz como recurso pedagógico no processo educacional: apresentação de um objeto de aprendizagem. In: XIII Congresso Internacional de Tecnologia na Educação. Pernambuco. Pernambuco: Senac, 2015. p. 1-12.

AUSUBEL, D. P.; NOVAK, J. D.; HANESIAN, H. Psicologia educacional. 1980. Interamericana.

BRENELLI, R. P. Espaço lúdico e diagnóstico em dificuldades de aprendizagem: contribuição do jogo de regras. In: SISTO, F. F. (Ed.). Dificuldades de aprendizagem no contexto psicopedagógico. Petrópolis: Vozes, 2001. p. 167-189.

CORREIA, R. F. M. As palavras cruzadas como ferramenta de transposição. Dissertação (Mestrado Profissional em Ensino de Física) — Universidade Regional do Cariri, Juazeiro do Norte, 2016.

DIOGO, R. C.; GOBARA, S. T. Sociedade, educação e ensino de física no Brasil: do Brasil Colônia ao fim da Era Vargas. 2007. Proceedings from Simpósio Nacional de Ensino de Física.
DOLZ, J.; NOVERRAZ, M.; SCHNEUWLY,

B. Sequências didáticas para o oral e a escrita: apresentação de um procedimento. In: Gêneros orais e escritos na escola. Campinas: Mercado de Letras, 2004. p. 95-128.

GARCIA, A. Gamificação como prática pedagógica docente no processo ensino e aprendizagem na temática da inclusão social. Dissertação (Programa de Pós-Graduação em Ensino de Ciências Humanas, Sociais e da Natureza) - Universidade Tecnológica Federal do Paraná, Londrina, 2015.

MIRANDA, R. M.; VANIN, V. R.; BECHARA, M. J. Uso de simulações em disciplinas básicas de mecânica em um curso de licenciatura em física. Encontro de Pesquisa em Ensino de Física, v. 9, n. 1, p. 1-12, 2004.

NASCIMENTO, C. A.; SANTOS, F. G. F. dos; FREIRE, R. O.; SOUSA, P. G. T. de; SILVA, D. S. da. Jogo lúdico como ferramenta pedagógica na aprendizagem de conceitos químicos. ConexõesCiência e Tecnologia, v. 14, n. 2, p. 14-20, 2020.

OLIVEIRA, L. P. d.; JUNIOR, H. R.; SCHIMIGUEL, J. Ensino de Matemática Financeira com Objeto de Aprendizagem: um estudo de caso. 2012.

OLIVEIRA, M. M. Sequência didática interativa no processo de formação de professores. 1. ed. Petrópolis: Vozes, 2013.

PEREIRA, A. L. L. A Utilização do Jogo como recurso de motivação e aprendizagem. Dissertação (Mestrado em Letras) - Universidade do Porto, Portugal, 2013.

PETRI, G.; BATTISTELLA, P. E.; CASSETTARI, F.; WANGENHEIM, C. G. von; HAUCK, J. Um quiz game para a revisão de conhecimentos em gerenciamento de projetos. In: Brazilian Symposium on Computers in Education (Simpósio Brasileiro de Informática na Educação). Florianópolis: SBIE, 2016. v. 27, n. 1, p. 320.

SALES, G. L.; CUNHA, J. L. L.; GONÇALVES, A. J.; SILVA, J. B. da; SANTOS, R. L. dos. Gamificação e ensinagem híbrida na sala de aula de física: metodologias ativas aplicadas aos espaços de aprendizagem e na prática docente. Conexões-Ciência e Tecnologia, v. 11, n. 2, p. 45-52, 2017.

SCHAEFFER, E. H. O jogo matemático como experiência de diálogo: análise fenomenológica 
da percepção de professores de matemática.

Dissertação (Mestrado em Educação para a Ciência e o

Ensino de Matemática) — Universidade Estadual de

Maringá, Maringá, 2006.

SILVA, J.; SALES, G.; ALVES, F. Didática da física: uma análise de seus elementos de natureza epistemológica, cognitiva e metodológica. Caderno Brasileiro de Ensino de Física, v. 35, n. 1, p. 20-41, 2018.

STUDART, N. Simulação, games e gamificação no ensino de física. Simpósio nacional de ensino de física, v. 21, n. 1, p. 1-17, 2015.

YAMAMOTO, I.; BARBETA, V. B. Simulações de experiências como ferramenta de demonstração virtual em aulas de teoria de física. Revista Brasileira de Ensino de Física, SciELO Brasil, v. 23, n. 1, p. 215-225, 2001. 